Supporting Information for

\title{
Metal-Free Thiophene-Sulfur Covalent Organic Frameworks: Precise and Controllable Synthesis of Catalytic Active Sites for Oxygen Reduction
}

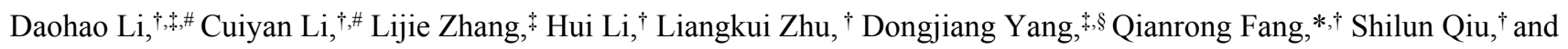
Xiangdong Yao*, $\uparrow, \S$

'State Key Laboratory of Inorganic Synthesis and Preparative Chemistry, College of Chemistry, Jilin University, Changchun 130012, P. R. China.

State Kay Laboratory of Bio-fibers and Eco-textiles, Collaborative Innovation Center for Marine Biomass Fibers, Materials and Textiles of Shandong Province, Institute of Marine Biobased Materials, School of Environmental Science and Engineering, Qingdao University, Qingdao 266071, P. R. China.

§Queensland Micro- and Nanotechnology Centre (QMNC), Griffith University, Nathan, Brisbane, Queensland 4111, Australia

*To whom correspondence should be addressed. E-mail: Qianrong Fang (qrfang@jlu.edu.cn); Xiangdong Yao (x.yao@griffith.edu.au; xdyao@jlu.edu.cn)

\section{Contents:}

\section{Experimental details}

2. Structural and morphology characterization

3. Electrochemical ORR performance

4. Theoretical computation section 


\section{Experimental detail}

Materials. All starting materials and solvents, unless otherwise noted, were obtained from J\&K Scientific LTD. 1,3,5-Tris(4-aminophenyl)benzene (TAPB) were acquired by Energy Chemical. 2,5-Thiophenedicarboxaldehyde (TDC) and terephthalaldehyde (PDA) were purchased from Shanghai Aladdin Biochemical Technology Co., Ltd. 2,2'-Bithiophene-5,5'-dicarboxaldehyde (bTDC) was provided by TCI. Mesitylene and 1,4-dioxane were obtained from J\&K Scientific LTD.

\subsection{Synthesis of COFs.}

\section{(1) Synthesis of JUC-527}

TAPB (0.1 mmol, $35.0 \mathrm{mg})$ and TDC (0.15 mmol, $21.0 \mathrm{mg})$ were weighted into a Pyrex tube (volume: ca. $20 \mathrm{ml}$ with a body length of $18 \mathrm{~cm}$, neck length of $9 \mathrm{~cm}$ ) and to the mixture was added mesitylene $(0.5 \mathrm{ml}), 1,4$-dioxane $(0.5 \mathrm{ml})$ and $0.1 \mathrm{ml}$ of aqueous acetic acid (6.0 $\mathrm{mol} / \mathrm{L})$. The tube was flash frozen at $77 \mathrm{~K}\left(\mathrm{LN}_{2}\right.$ bath), evacuated to an internal pressure of $0.15 \mathrm{mmHg}$ and flame sealed. Upon sealing the length of the tube was reduced to $\mathrm{ca} .13 \mathrm{~cm}$. The reaction mixture was heated at $120{ }^{\circ} \mathrm{C}$ for $72 \mathrm{~h}$ to afford a orange precipitate which was isolated by filtration over a medium glass frit and washed with anhydrous acetone $(3 \times 20 \mathrm{ml})$. The yield is about 55.35\% (31.0 mg). The solvent was removed under vacuum at $80{ }^{\circ} \mathrm{C}$ to afford the corresponding products as yellow powder in isolated yields of 78\% for JUC-527.

\section{(2) Synthesis of JUC-528}

In a similar procedure of JUC-527, TAPB (0.05 mmol, $17.7 \mathrm{mg})$ and bTDC (0.075 mmol, 16.67 $\mathrm{mg}$ ) were weighted into a Pyrex tube (volume: ca. $20 \mathrm{ml}$ with a body length of $18 \mathrm{~cm}$, neck length of $9 \mathrm{~cm})$ and to the mixture was added butanol $(0.5 \mathrm{ml}), 1,2$-dichlorobenzene $(0.5 \mathrm{ml})$ and $0.1 \mathrm{ml}$ of aqueous acetic acid $(6.0 \mathrm{~mol} / \mathrm{L})$. The tube was flash frozen at $77 \mathrm{~K}\left(\mathrm{LN}_{2}\right.$ bath), evacuated to an internal pressure of $0.15 \mathrm{mmHg}$ and flame sealed. Upon sealing the length of the tube was reduced to ca. $13 \mathrm{~cm}$. The reaction mixture was heated at $120{ }^{\circ} \mathrm{C}$ for $72 \mathrm{~h}$ to afford a Reddish brown precipitate which was isolated by filtration over a medium glass frit and washed with anhydrous acetone $(3 \times 20$ $\mathrm{ml})$. The yield is about $65.5 \%(22.5 \mathrm{mg})$. The solvent was removed under vacuum at $80{ }^{\circ} \mathrm{C}$ to afford the corresponding products as orange powder in isolated yields of 75\% for JUC-528.

\section{(3) Synthesis of PDA-TAPB-COF}


TAPB (55 mg, $0.16 \mathrm{mmol})$ and PDA (31 mg, $0.23 \mathrm{mmol})$ were combined in a scintillation vial with a dioxane/mesitylene solution $(4: 1 \mathrm{v} / \mathrm{v}, 6.3 \mathrm{~mL})$. The solution was heated to $70{ }^{\circ} \mathrm{C}$ for 3 minutes to ensure dissolution and then cooled to room temperature. Distilled $\mathrm{H}_{2} \mathrm{O}(1.2$ $\mathrm{mL}$ ) was added to the solution, followed by glacial $\mathrm{CH}_{3} \mathrm{COOH}(1.8 \mathrm{~mL})$. The resulting suspension was sealed and heated to $70{ }^{\circ} \mathrm{C}$ for $72 \mathrm{~h}$. The COF solid was isolated by filtration, rinsed with toluene, and subsequently dried under vacuum, yielding a yellow powder (66.0 $\mathrm{mg}, 85 \%$ yield).

\subsection{Characterizations}

The FTIR spectra (KBr) were obtained using a SHIMADZU IRAffinity-1 Fourier transform infrared spectrophotometer. Thermogravimetric analysis (TGA) was recorded on a SHIMADZU DTG-60 thermal analyzer under $\mathrm{N}_{2}$. The operational range of the instrument was from $30{ }^{\circ} \mathrm{C}$ to $800{ }^{\circ} \mathrm{C}$ at a heating rate of $10{ }^{\circ} \mathrm{C} \mathrm{min}^{-1}$ with $\mathrm{N}_{2}$ flow rate of $30 \mathrm{~mL} \mathrm{~min}{ }^{-1}$. PXRD data were collected on a PANalytical B.V. Empyrean powder diffractometer using a $\mathrm{Cu} \mathrm{K} \alpha$ source $(\lambda=1.5418 \AA)$ over the range of $2 \theta=2.0-40.0^{\circ}$ with a step size of $0.02^{\circ}$ and $2 \mathrm{~s}$ per step. The sorption isotherm for $\mathrm{N}_{2}$ was measured by using a Quantachrome Autosorb-IQ analyzer with ultrahigh-purity gas (99.999\% purity). To estimate pore size distributions, nonlocal density functional theory (NLDFT) was applied to analyze the $\mathrm{N}_{2}$ isotherm based on the model of $\mathrm{N}_{2} @ 77 \mathrm{~K}$ on carbon with slit pores and the method of non-negative regularization. The SEM images were obtained on JEOL JSM6700 scanning electron microscope. TEM and high-resolution TEM (HRTEM) images were obtained using a JEM-2100F with an accelerating voltage of $200 \mathrm{kV}$.

\subsection{Electrochemical Measurements}

The ORR catalytic activities of prepared four COFs catalysts were measured in $0.1 \mathrm{M} \mathrm{KOH}$ solution. An ink of the catalyst was prepared by mixing $3 \mathrm{mg}$ of catalyst powder and $3 \mathrm{mg}$ acetylene black with $250 \mu \mathrm{l}$ of ethanol, $250 \mu \mathrm{l}$ of $\mathrm{H}_{2} \mathrm{O}$, and $25 \mu \mathrm{l} 5 \mathrm{wt} \%$ Nafion solution, and further placed in an ultrasonic bath. $6 \mu \mathrm{L}$ of the solution was loaded onto the electrode. The RDE measurements were performed in a three-electrode, one-compartment cell at room temperature, equipped with a graphite rod counter electrode and a $\mathrm{Ag} / \mathrm{AgCl}$ reference electrode. Linear sweep voltammetry (LSV) was performed in $\mathrm{N}_{2}$-saturated and $\mathrm{O}_{2}$-saturated $0.1 \mathrm{M} \mathrm{KOH}$ at a scan rate of $10 \mathrm{mV} \mathrm{s}^{-1}$ under various electrode rotation rates $(400,625,900,1025,1600,2025$ and $2500 \mathrm{rpm}$, respectively). Long-term stability test was conducted by measuring the current changes of the catalyst at a fixed potential of $0.7 \mathrm{~V}$ (vs RHE) at a rotation speed of $1600 \mathrm{rpm}$ in $\mathrm{O}_{2}$-saturated electrolyte using on a CHI $760 \mathrm{E}$ electrochemical workstation. Methanol tolerance tests were performed by chronoamperometric 
measurement at $0.7 \mathrm{~V}$ (vs RHE) at a rotating speed of $1600 \mathrm{rpm}$ (methanol was dropped into the electrolytes at $200 \mathrm{~s})$.

The turnover frequency (TOF) value is calculated according to the following equation:

$\mathrm{TOF}=(\mathrm{J} \times \mathrm{A}) /(4 \times \mathrm{F} \times \mathrm{n})$

where $\mathrm{J}$ is the current density at a given potential $(0.7 \mathrm{~V}), \mathrm{A}$ is the surface area of the electrode $\left(0.0707 \mathrm{~cm}^{2}\right)$, the number of 4 represents 4 electrons $/ \mathrm{mol}$ of $\mathrm{O} 2, \mathrm{~F}$ is the Faraday constant $(96485.3$ $\mathrm{C} / \mathrm{mol}$ ), and $\mathrm{n}$ stands for the number of moles of $\mathrm{S}$ atoms in samples.

For the zinc-air battery, the air electrodes were prepared by uniformly coating the as-prepared catalyst ink onto carbon paper and then drying it at $100{ }^{\circ} \mathrm{C}$ for $2 \mathrm{~h}$. The mass loading was $1.0 \mathrm{mg}$ $\mathrm{cm}^{-2}$. A zinc plate was used as the anode. Both electrodes were assembled into a home-built electrochemical battery with the electrolyte being $6.0 \mathrm{M} \mathrm{KOH}$.

\subsection{Computational Details}

B3LYP hybrid density functional theory of Gaussian $09^{1}$ was employed with a basis set of 6-31G $(d, p)^{2-3}$. Density of State (DOS) was calculated by Vienna ab initio Simulation Package (VASP) code $^{4}$. The exchange correlation energy was modelled by using Perdew-Burke-Ernzerhof (PBE) functional ${ }^{5}$ within the generalized gradient approximation (GGA). The projector augmented wave (PAW) pseudo-potentials ${ }^{6}$ were used to describe ionic cores. The cutoff energy of $500 \mathrm{eV}$ was adopted. The convergence threshold for the iteration in self-consistent-field (SCF) was set to be $10^{-4}$ $\mathrm{eV}$. Denser k-points $(1 \times 1 \times 1)$ were used for the electronic structure calculations. A large vacuum slab of $20 \AA$ was inserted in $\mathrm{z}$ direction for surface isolation to prevent interaction between two neighboring surfaces. The overall ORR in an acid environment can be written as follows:

$$
\begin{gathered}
\mathrm{O}_{2}(g)+\mathrm{H}_{2} \mathrm{O}(\mathrm{l})+e^{-}+* \rightarrow \mathrm{OOH}^{*}+\mathrm{OH}^{-} \\
\mathrm{OOH}^{*}+e^{-} \rightarrow \mathrm{O}^{*}+\mathrm{OH}^{-} \\
\mathrm{O}^{*}+\mathrm{H} 2 \mathrm{O}(\mathrm{l})+e^{-} \rightarrow \mathrm{OH}^{*}+\mathrm{OH}^{-} \\
O H^{*}+e^{-} \rightarrow \mathrm{OH}^{-}+*
\end{gathered}
$$

For each elementary step, the Gibbs reaction free energy $\Delta \mathrm{G}$ is defined as the difference between free energies of the initial and final states and is given by the expression

$$
\Delta \mathrm{G}=\Delta \mathrm{E}+\Delta \mathrm{ZPE}-\mathrm{T} \Delta \mathrm{S}+\Delta G_{U}+\Delta G_{P H}
$$

where $\Delta \mathrm{E}$ is the reaction energy of reactant and product molecules adsorbed on catalyst surface, obtained from DFT calculations; $\triangle \mathrm{ZPE}$ and $\Delta \mathrm{S}$ are the change in zero point energies and entropy due to the reaction. Each step of $\Delta G$ was obtained as follows: 


$$
\begin{aligned}
& \Delta G_{\mathrm{a}}=\Delta G_{\mathrm{OOH}^{*}}-e U+\Delta G_{\mathrm{H}^{+}}-4.92 \mathrm{eV} \\
& \Delta G_{\mathrm{b}}=\Delta G_{\mathrm{O}^{*}}-\Delta G_{\mathrm{OOH}^{*}}-e U+\Delta G_{\mathrm{H}^{+}} \\
& \Delta G_{\mathrm{c}}=\Delta G_{\mathrm{OH}^{*}}-\Delta G_{\mathrm{O}^{*}}-e U+\Delta G_{\mathrm{H}^{+}} \\
& \Delta G_{\mathrm{d}}=-\Delta G_{\mathrm{OH}^{*}}-e U+\Delta G_{\mathrm{H}^{+}}
\end{aligned}
$$

\section{REFERENCES}

(1) Frisch, M. J.; Trucks, G. W.; Schlegel, H. B.; Scuseria, G. E.; Robb, M. A.; Cheeseman, J. R.;

Scalmani, G.; Barone, V.; Mennucci, B.; Petersson, G. A., et al. Gaussian 09, Revision A.02; Gaussian, Inc.: Wallingford CT, 2009.

(2) Hariharan, P. C.; Pople, J. A. The Influence of Polarization Functions on Molecular Orbital Hydrogenation Energies. Theor. Chem. Acc. 1973, 28, 213-222.

(3) Francl, M. M.; Pietro, W. J.; Hehre, W. J.; Binkley, J. S.; DeFrees, D. J.; Pople, J. A.; Gordon, M. S. Self-Consistent Molecular Orbital Methods. XXIII. A Polarization-Type Basis Set for Second-Row Elements. J. Chem. Phys. 1982, 77, 3654-3665.

(4) Kresse, G.; Furthmüller, J. Efficiency of ab-Initio Total Energy Calculations for Metals and Semiconductors using A Plane-Wave Basis Set. Comput. Mater. Sci. 1996, 6, 15-50.

(5) Perdew, J.; Burke, K.; Ernzerhof, M. Generalized Gradient Approximation Made Simple. Phys. Rev. Lett. 1996, 77, 3865-3868.

(6) Kresse, G.; Joubert, D. From Ultrasoft Pseudopotentials to The Projector Augmented-Wave Method. Phys. Rev. B 1999, 59, 1758-1775. 


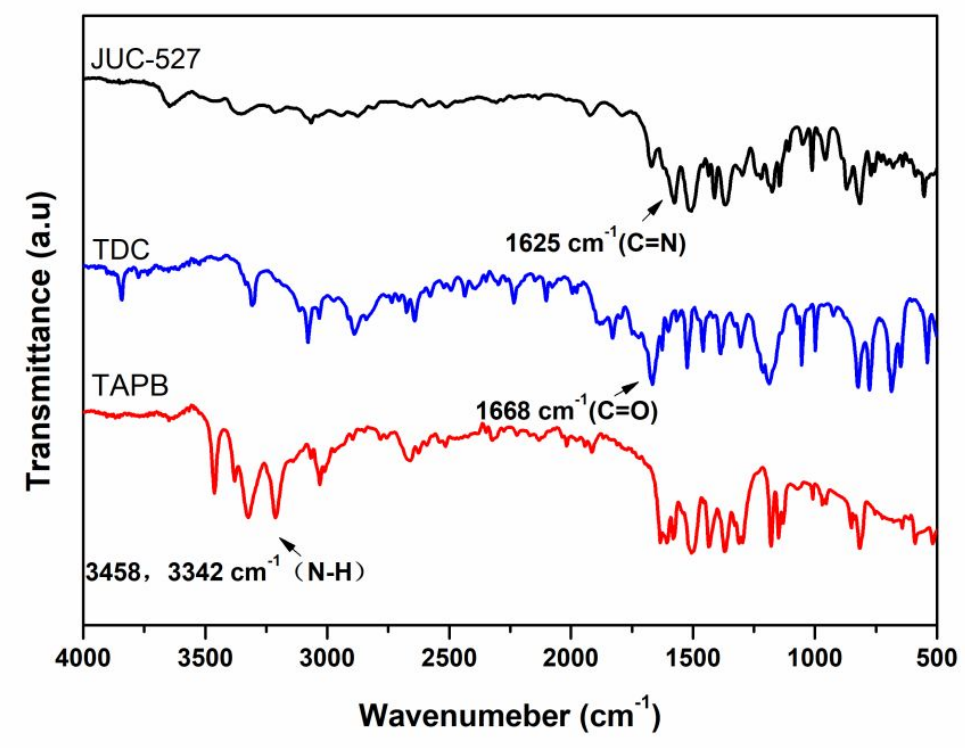

Figure S1. FTIR spectra of TDC, TAPB, and JUC-527.

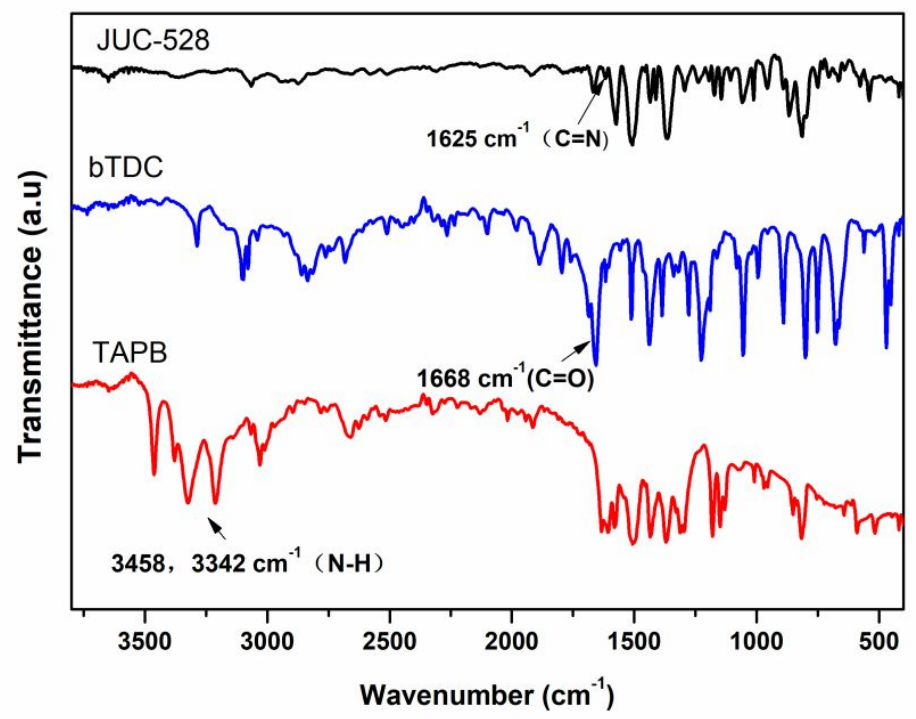

Figure S2. FTIR spectra of bTDC, TAPB, and JUC-528. 


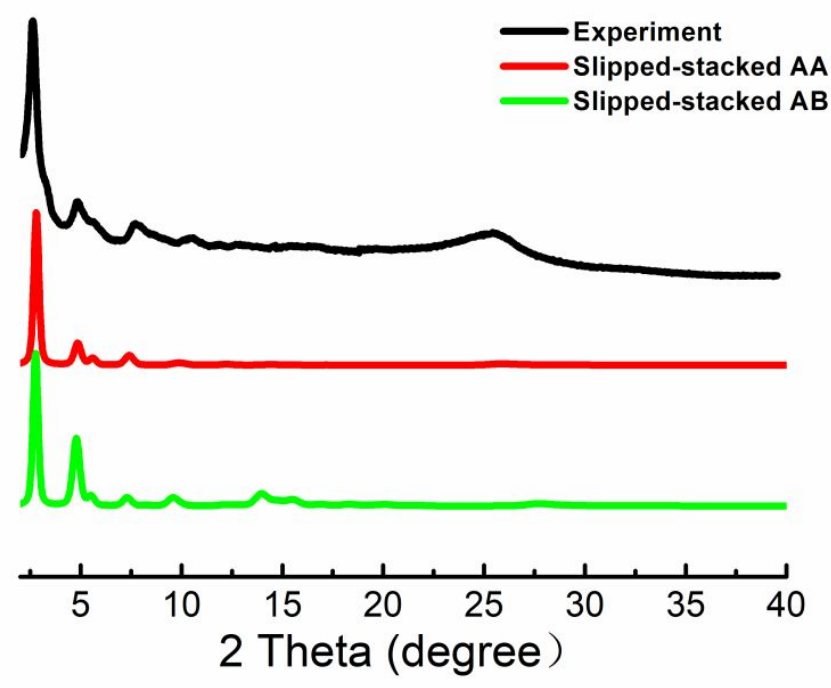

Figure S3. Calculated and experiment PXRD pattern of JUC-527.

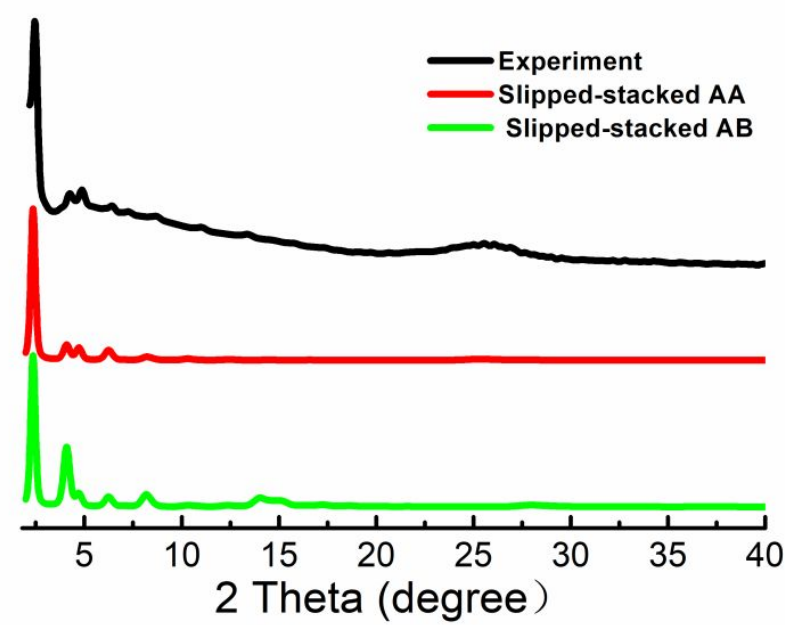

Figure S4. Calculated and experiment PXRD pattern of JUC-528. 
Table S1. Unit cell parameters and fractional atomic coordinates for JUC-527 calculated on the basis of staggered heg net.

\begin{tabular}{|c|c|c|c|}
\hline \multicolumn{2}{|c|}{ Space group } & \multicolumn{2}{|c|}{$P-6$} \\
\hline \multicolumn{2}{|c|}{ Calculated unit cell } & \multicolumn{2}{|c|}{$a=b=35.9059 \AA, c=3.5420 \AA, \alpha=\beta=90^{\circ}, \gamma=120^{\circ}$} \\
\hline \multicolumn{2}{|c|}{ Measured unit cell } & \multicolumn{2}{|c|}{$a=b=35.9218 \AA ⿻, c=3.5630 \AA, \alpha=\beta=90^{\circ}, \gamma=120^{\circ}$} \\
\hline \multicolumn{2}{|c|}{ Pawley refinement } & \multicolumn{2}{|c|}{$R_{\mathrm{p}}=1.69 \%, w R_{\mathrm{p}}=1.92 \%$} \\
\hline atoms & $\mathrm{x}$ & $\mathrm{y}$ & $\mathrm{z}$ \\
\hline $\mathrm{C} 1$ & 0.28831 & 0.64876 & 0 \\
\hline $\mathrm{C} 2$ & 0.31564 & 0.69348 & 0 \\
\hline $\mathrm{C} 3$ & 0.43383 & 0.77722 & 0 \\
\hline $\mathrm{C} 4$ & 0.46069 & 0.82182 & 0 \\
\hline $\mathrm{C} 5$ & 0.44304 & 0.84899 & 0 \\
\hline C6 & 0.39839 & 0.83097 & 0 \\
\hline $\mathrm{C} 7$ & 0.37154 & 0.78636 & 0 \\
\hline $\mathrm{C} 8$ & 0.38895 & 0.75898 & 0 \\
\hline C9 & 0.51128 & 0.91423 & 0 \\
\hline N10 & 0.46966 & 0.89482 & 0 \\
\hline $\mathrm{C} 11$ & 0.71017 & 0.36615 & 0 \\
\hline $\mathrm{C} 12$ & 0.69911 & 0.32277 & 0 \\
\hline $\mathrm{C} 13$ & 0.60158 & 0.21116 & 0 \\
\hline $\mathrm{C} 14$ & 0.59101 & 0.16807 & 0 \\
\hline $\mathrm{C} 15$ & 0.62355 & 0.15724 & 0 \\
\hline $\mathrm{C} 16$ & 0.66657 & 0.18997 & 0 \\
\hline $\mathrm{C} 17$ & 0.67713 & 0.23306 & 0 \\
\hline $\mathrm{C} 18$ & 0.64476 & 0.24414 & 0 \\
\hline $\mathrm{C} 19$ & 0.57486 & 0.08110 & 0 \\
\hline N20 & 0.61380 & 0.11341 & 0 \\
\hline $\mathrm{C} 21$ & 0.42414 & 0.46294 & 0 \\
\hline $\mathrm{C} 22$ & 0.40098 & 0.41868 & 0 \\
\hline $\mathrm{C} 23$ & 0.42772 & 0.40163 & 0 \\
\hline $\mathrm{C} 24$ & 0.47037 & 0.43361 & 0 \\
\hline $\mathrm{S} 25$ & 0.47879 & 0.48477 & 0 \\
\hline $\mathrm{H} 26$ & 0.30150 & 0.71571 & 0 \\
\hline $\mathrm{H} 27$ & 0.44831 & 0.75529 & 0 \\
\hline $\mathrm{H} 28$ & 0.49710 & 0.83630 & 0 \\
\hline
\end{tabular}




\begin{tabular}{|c|c|c|c|}
\hline H29 & 0.38369 & 0.85271 & 0 \\
\hline H30 & 0.33513 & 0.77186 & 0 \\
\hline H31 & 0.52779 & 0.89414 & 0 \\
\hline H32 & 0.72539 & 0.31378 & 0 \\
\hline H33 & 0.57504 & 0.21979 & 0 \\
\hline H34 & 0.55583 & 0.14153 & 0 \\
\hline H35 & 0.69327 & 0.18156 & 0 \\
\hline H36 & 0.71229 & 0.25961 & 0 \\
\hline H37 & 0.54693 & 0.08769 & 0 \\
\hline H38 & 0.36433 & 0.40122 & 0 \\
\hline H39 & 0.41355 & 0.36527 & 0 \\
\hline
\end{tabular}

Table S2. Unit cell parameters and fractional atomic coordinates for JUC-528 calculated on the basis of staggered heg net.

\begin{tabular}{|c|c|c|c|}
\hline \multicolumn{2}{|c|}{ Space group } & \multicolumn{2}{|c|}{$P-6$} \\
\hline \multicolumn{2}{|c|}{ Calculated unit cell } & $a=b=42.4546 \AA, c=3.5502 \AA, \alpha=\beta=90^{\circ}, \gamma=120^{\circ}$ \\
\hline \multicolumn{3}{|c|}{ Measured unit cell } & $a=b=42.8965 \AA, c=3.9522 \AA, \alpha=\beta=90^{\circ}, \gamma=120^{\circ}$ \\
\hline \multicolumn{2}{|c|}{ Pawley refinement $R_{\mathrm{p}}=1.58 \%, w R_{\mathrm{p}}=1.82 \%$} \\
\hline atoms & $\mathrm{x}$ & 0.64751 & $\mathrm{z}$ \\
\hline C1 & 0.35121 & 0.62983 & 0 \\
\hline C2 & 0.31428 & 0.35512 & 0 \\
\hline C3 & 0.65161 & 0.36998 & 0 \\
\hline C4 & 0.68834 & 0.36344 & 0 \\
\hline C5 & 0.59744 & 0.38576 & 0 \\
\hline C6 & 0.58198 & 0.42359 & 0 \\
\hline C7 & 0.60413 & 0.43897 & 0 \\
\hline C8 & 0.64210 & 0.41663 & 0 \\
\hline C9 & 0.65755 & 0.37869 & 0 \\
\hline C10 & 0.63533 & 0.48092 & 0 \\
\hline C11 & 0.60584 & 0.44570 & 0 \\
\hline N12 & 0.58744 & 0.48331 & 0.52646 \\
\hline S13 & 0.54122 & 0.55368 & 0 \\
\hline C14 & 0.54763 & & 0 \\
\hline C15 & 0.58364 & & 0 \\
\hline
\end{tabular}




\begin{tabular}{|c|c|c|c|}
\hline $\mathrm{C} 16$ & 0.60663 & 0.53971 & 0 \\
\hline $\mathrm{C} 17$ & 0.58747 & 0.50230 & 0 \\
\hline $\mathrm{S} 18$ & 0.52372 & 0.57710 & 0 \\
\hline C19 & 0.47759 & 0.55821 & 0 \\
\hline $\mathrm{C} 20$ & 0.45834 & 0.52070 & 0 \\
\hline $\mathrm{C} 21$ & 0.48130 & 0.50671 & 0 \\
\hline $\mathrm{C} 22$ & 0.51730 & 0.53394 & 0 \\
\hline $\mathrm{N} 23$ & 0.42533 & 0.56617 & 0 \\
\hline $\mathrm{C} 24$ & 0.46040 & 0.58072 & 0 \\
\hline $\mathrm{C} 25$ & 0.42699 & 0.62531 & 0 \\
\hline $\mathrm{C} 26$ & 0.40867 & 0.64496 & 0 \\
\hline $\mathrm{C} 27$ & 0.37056 & 0.62679 & 0 \\
\hline $\mathrm{C} 28$ & 0.35106 & 0.58866 & 0 \\
\hline $\mathrm{C} 29$ & 0.36938 & 0.56899 & 0 \\
\hline $\mathrm{C} 30$ & 0.40738 & 0.58712 & 0 \\
\hline H31 & 0.29812 & 0.59883 & 0 \\
\hline H32 & 0.70669 & 0.40080 & 0 \\
\hline H33 & 0.57922 & 0.33260 & 0 \\
\hline H34 & 0.55114 & 0.37315 & 0 \\
\hline H35 & 0.66045 & 0.46979 & 0 \\
\hline H36 & 0.68838 & 0.42924 & 0 \\
\hline H37 & 0.63684 & 0.49571 & 0 \\
\hline H38 & 0.59089 & 0.58342 & 0 \\
\hline H39 & 0.63733 & 0.55880 & 0 \\
\hline $\mathrm{H} 40$ & 0.42734 & 0.50561 & 0 \\
\hline H41 & 0.46968 & 0.47600 & 0 \\
\hline $\mathrm{H} 42$ & 0.47846 & 0.61158 & 0 \\
\hline $\mathrm{H} 43$ & 0.45799 & 0.64027 & 0 \\
\hline H44 & 0.42471 & 0.67596 & 0 \\
\hline $\mathrm{H} 45$ & 0.32006 & 0.57351 & 0 \\
\hline H46 & 0.35333 & 0.53799 & 0 \\
\hline
\end{tabular}




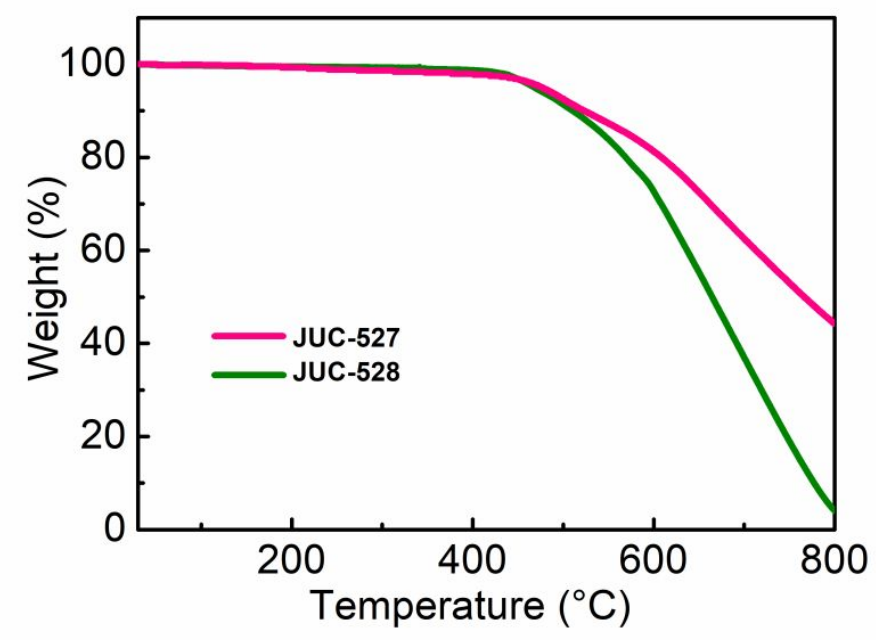

Figure S5. TGA curves of JUC-527 and JUC-528 in $\mathrm{N}_{2}$ atmosphere.

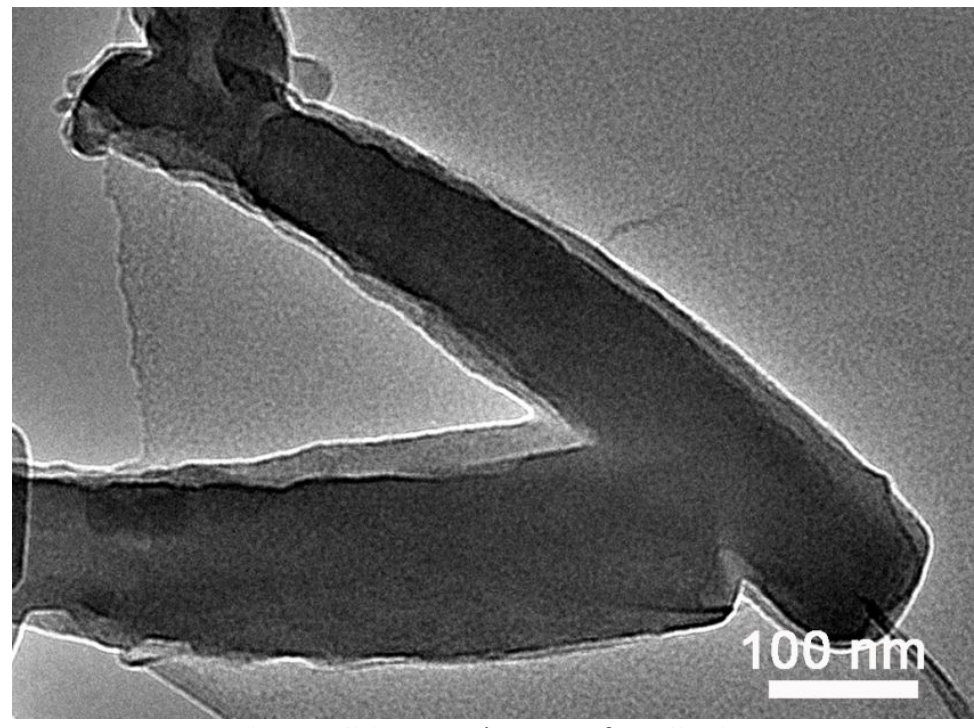

Figure S6. TEM image of JUC-527.

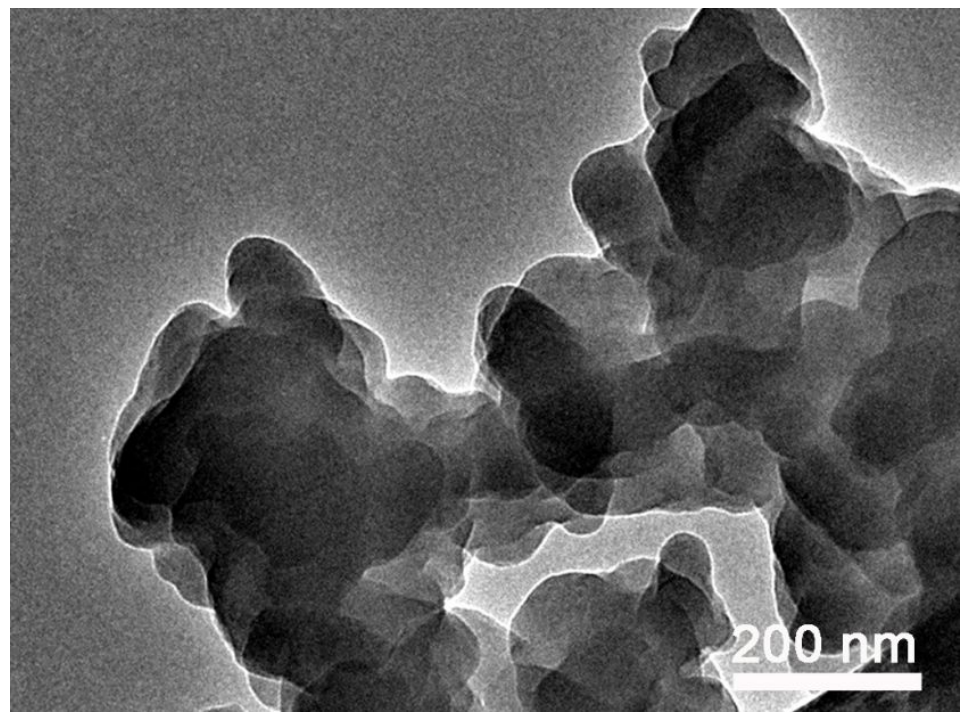

Figure S7. TEM image of JUC-528. 


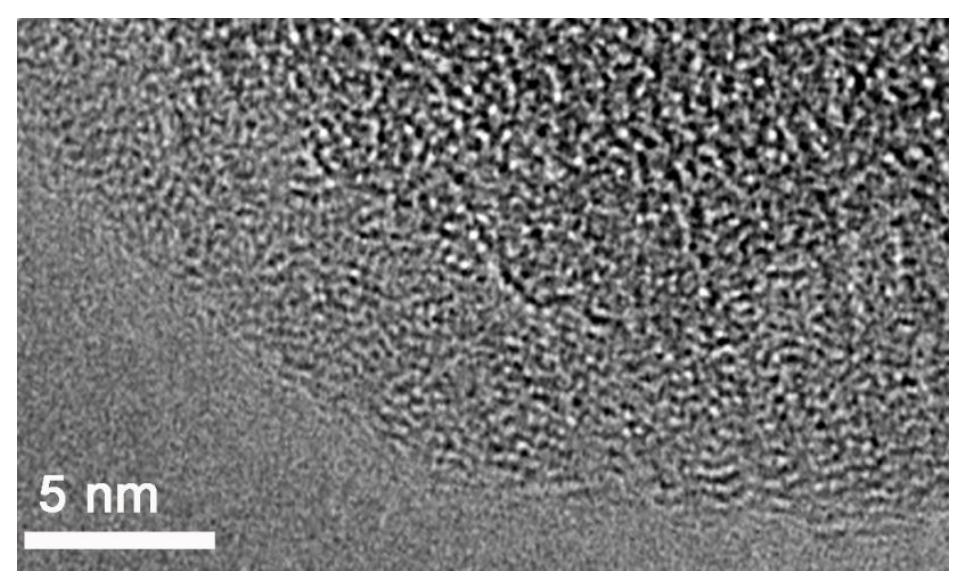

Figure S8. HRTEM image of JUC-527.

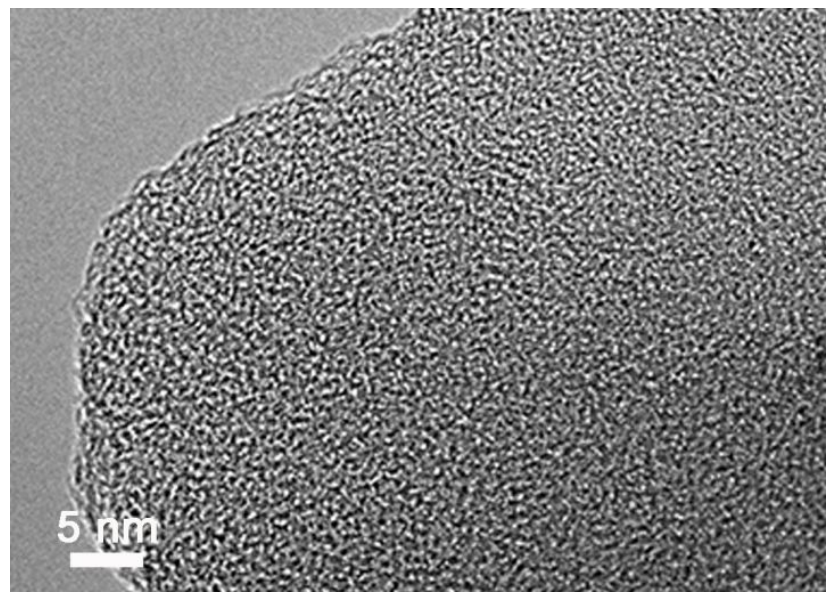

Figure S9. HRTEM image of JUC-528.

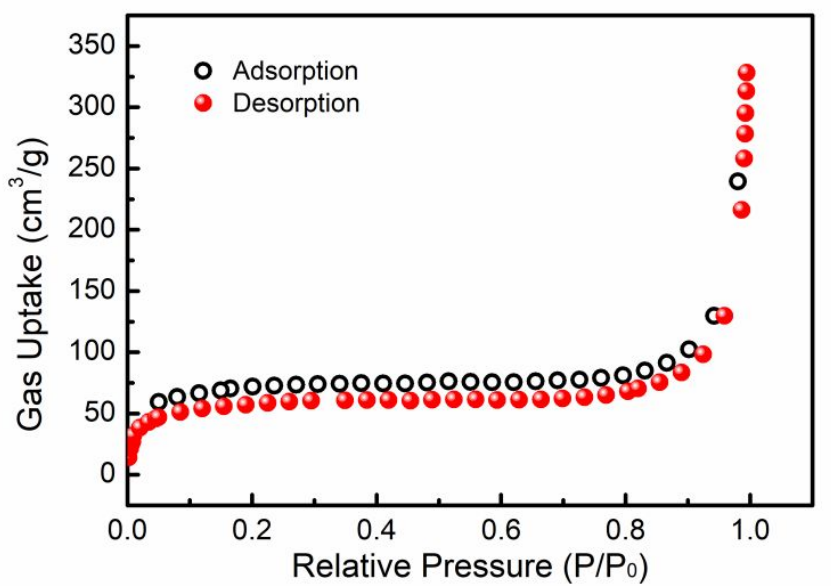

Figure S10. $\mathrm{N}_{2}$ adsorption-desorption isotherms of JUC-527. 


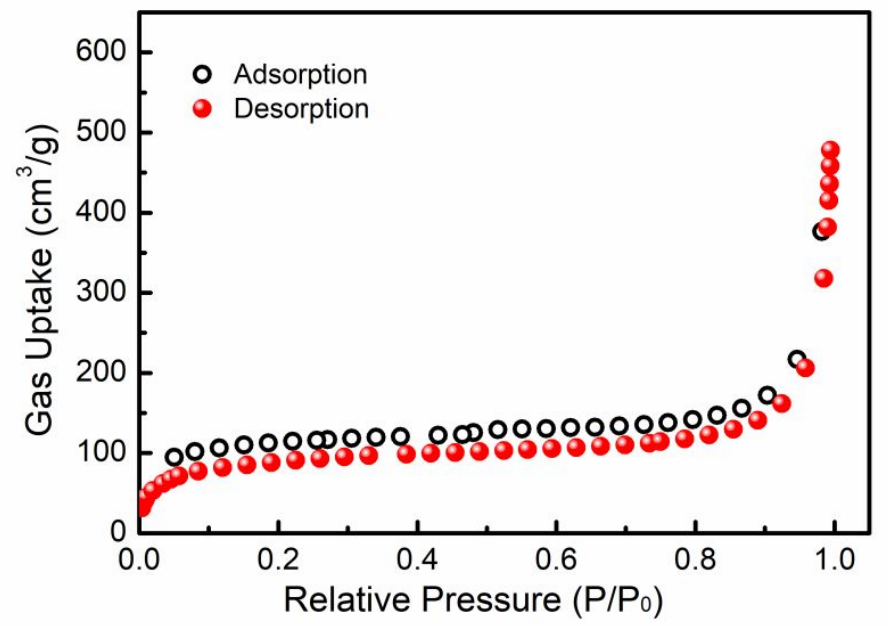

Figure S11. $\mathrm{N}_{2}$ adsorption-desorption isotherms of JUC-528.

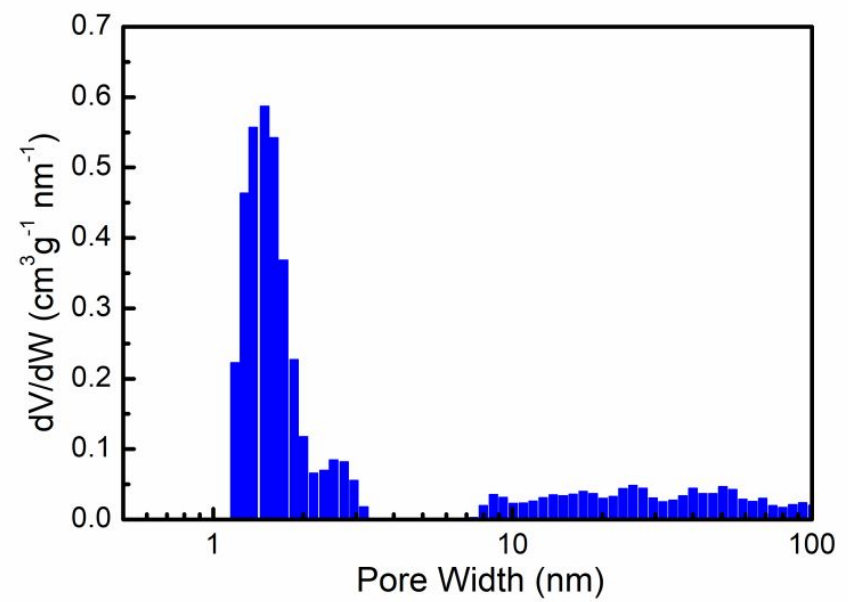

Figure S12. The pore size distribution curve of JUC-527.

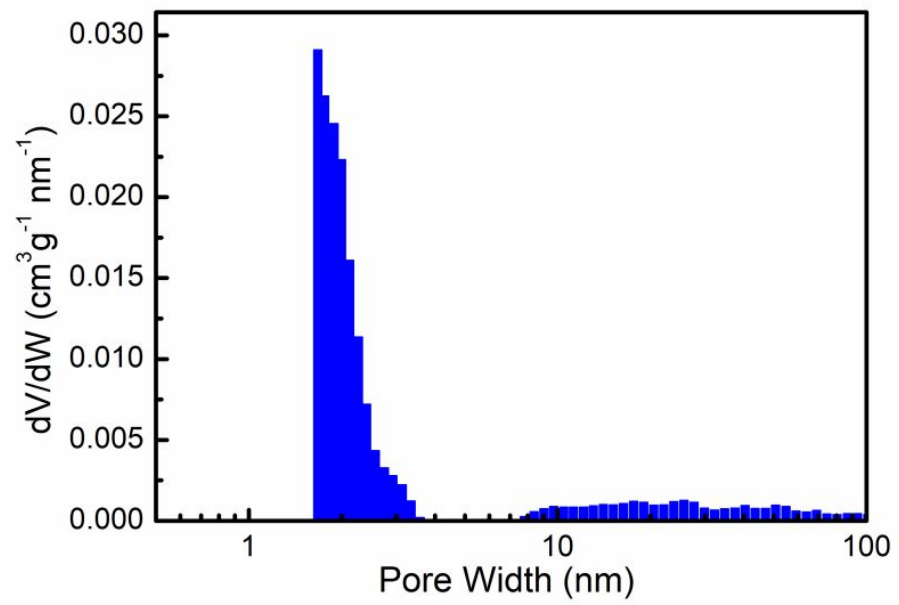

Figure S13. The corresponding pore size distribution curve of JUC-528. 


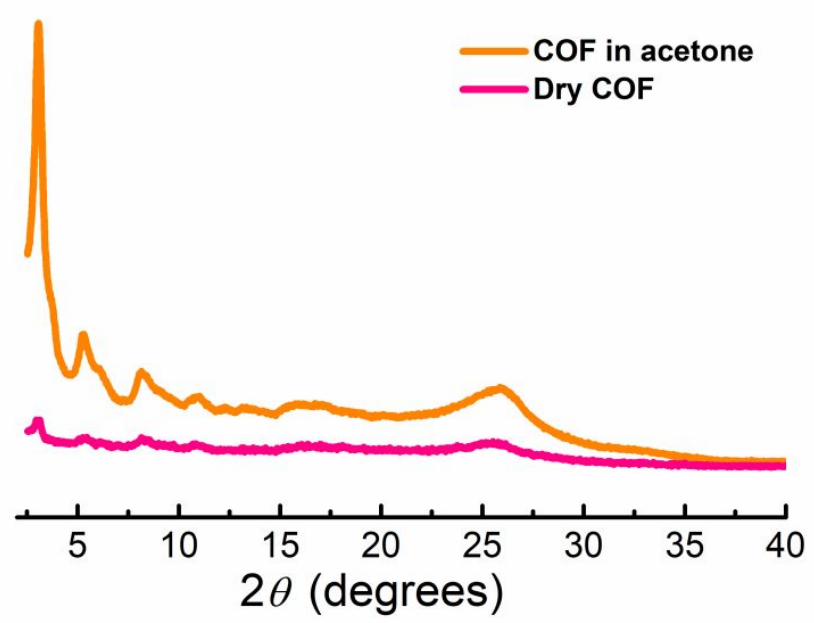

Figure S14. PXRD patterns of JUC-527 in acetone and dry JUC-527.

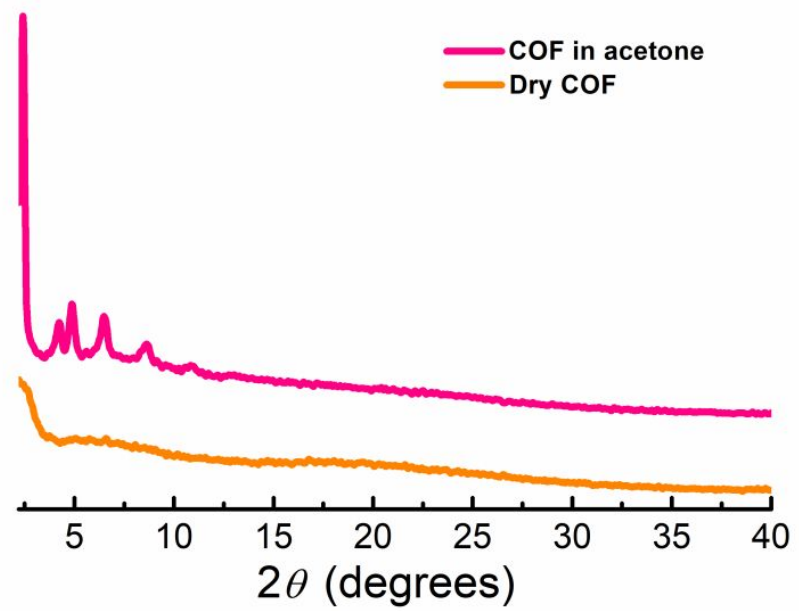

Figure S15. PXRD patterns of JUC-528 in acetone and dry JUC-528.

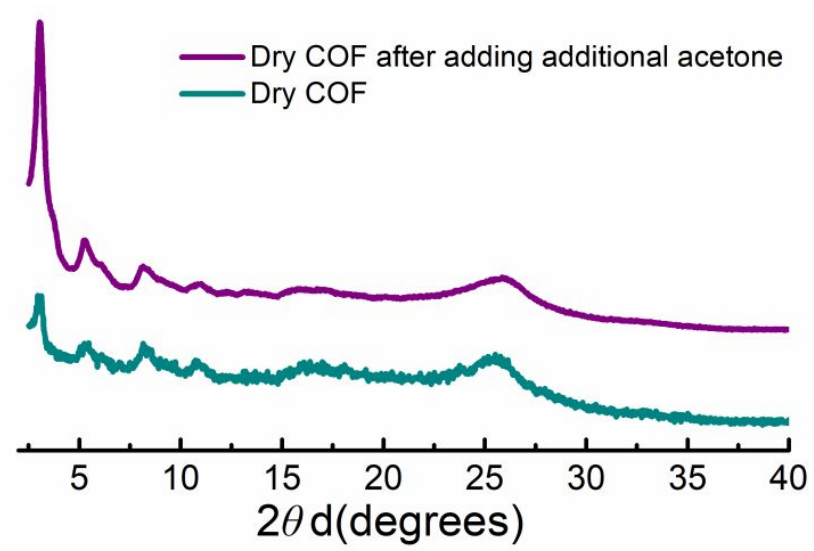

Figure S16. PXRD patterns of dry JUC-527 and after adding additional acetone. 


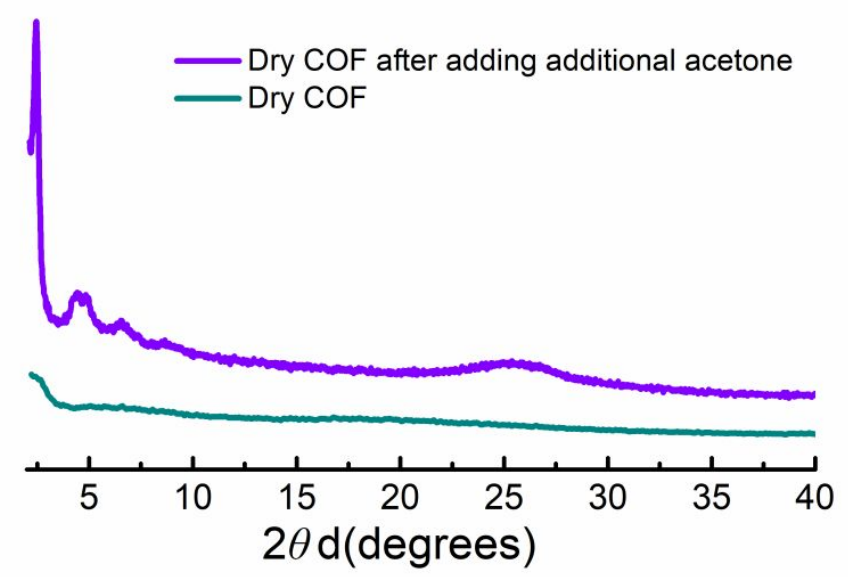

Figure S17. PXRD patterns of dry JUC-528 and after adding additional acetone.

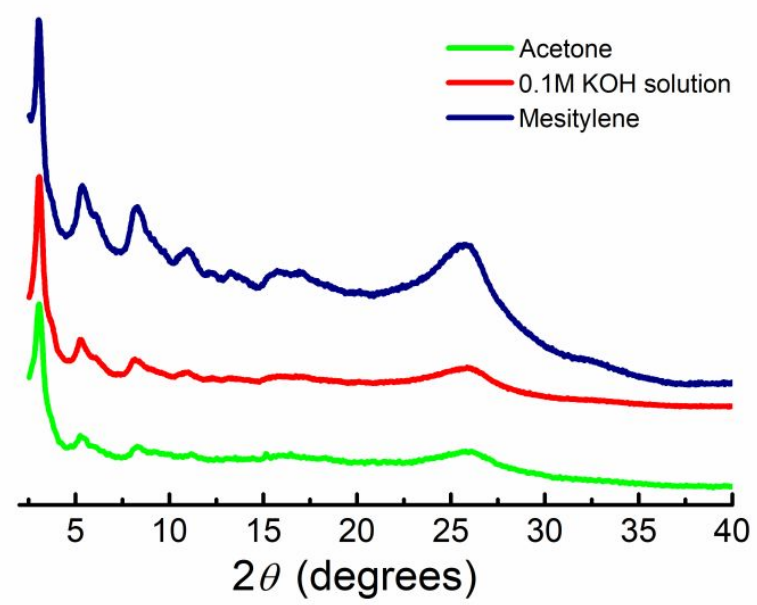

Figure S18. PXRD patterns of JUC-527 in acetone and $0.1 \mathrm{M} \mathrm{KOH}$ acetone.

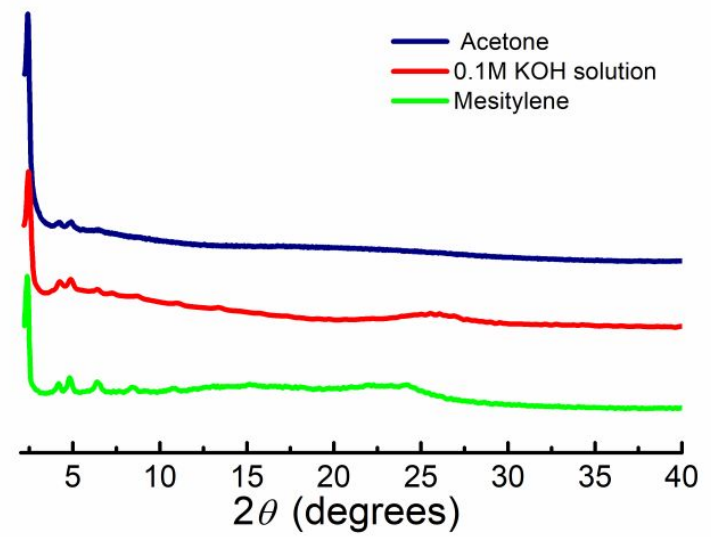

Figure S19. PXRD patterns of JUC-528 in acetone and 0.1 M KOH acetone. 


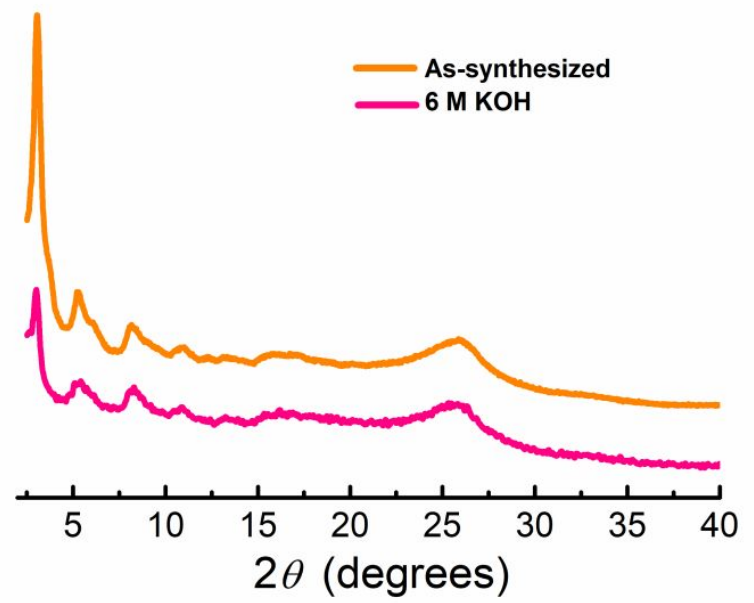

Figure S20. PXRD patterns of JUC-527 before and after treatment under $6.0 \mathrm{M} \mathrm{KOH}$ for 3 days.

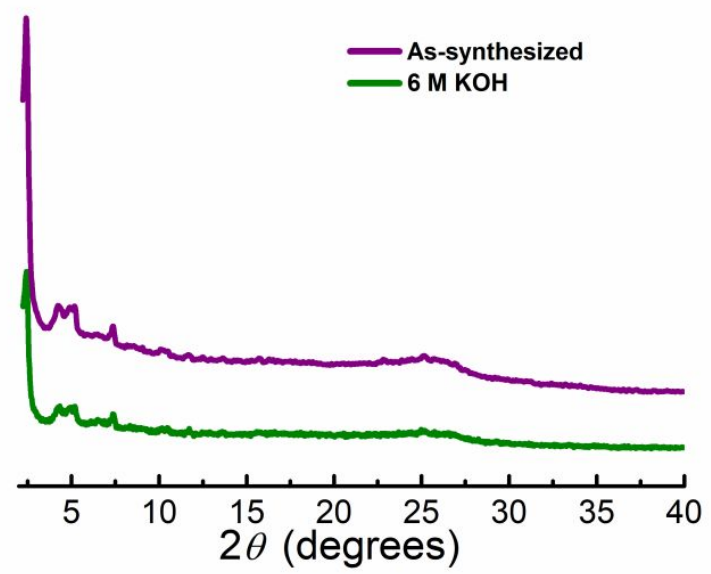

Figure S21. PXRD patterns of JUC-528 before and after treatment under $6.0 \mathrm{M} \mathrm{KOH}$ for 3 days. 


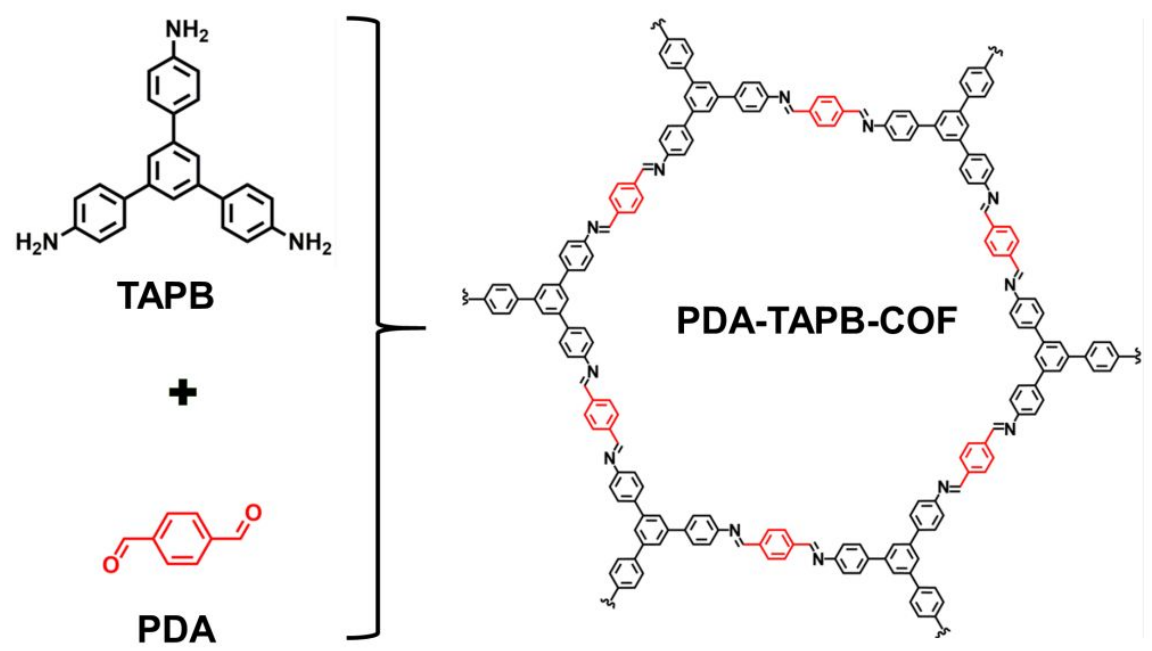

Figure S22. Syntheses and chemical structures of PDA-TAPB-COF.

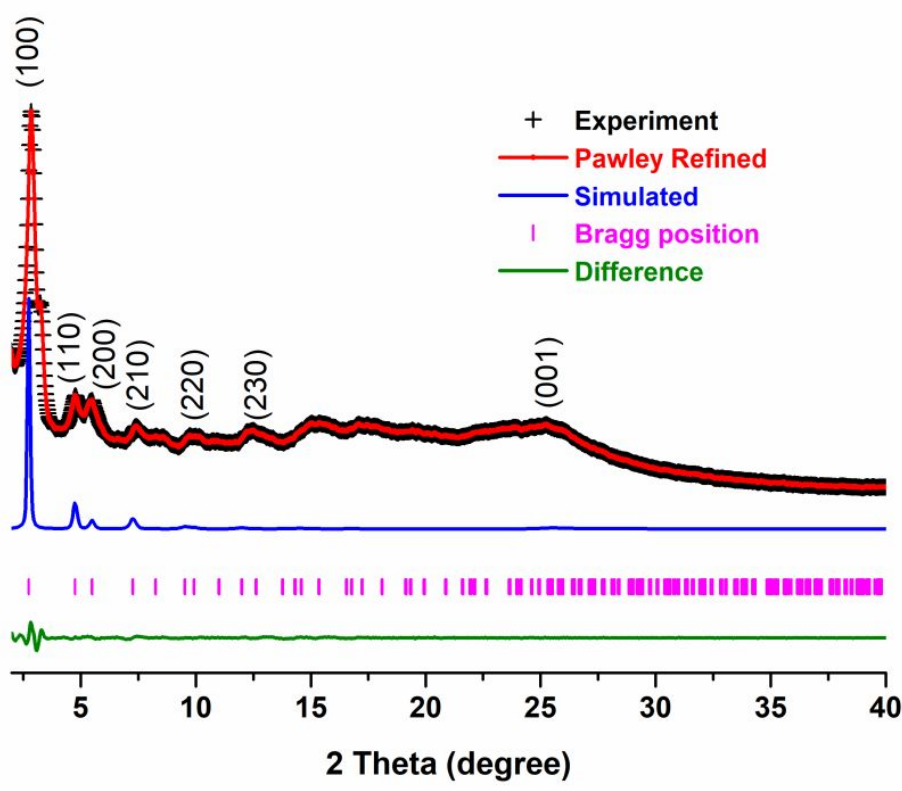

Figure S23. PXRD patterns of PDA-TAPB-COF. 


\section{Electrochemical ORR performance}

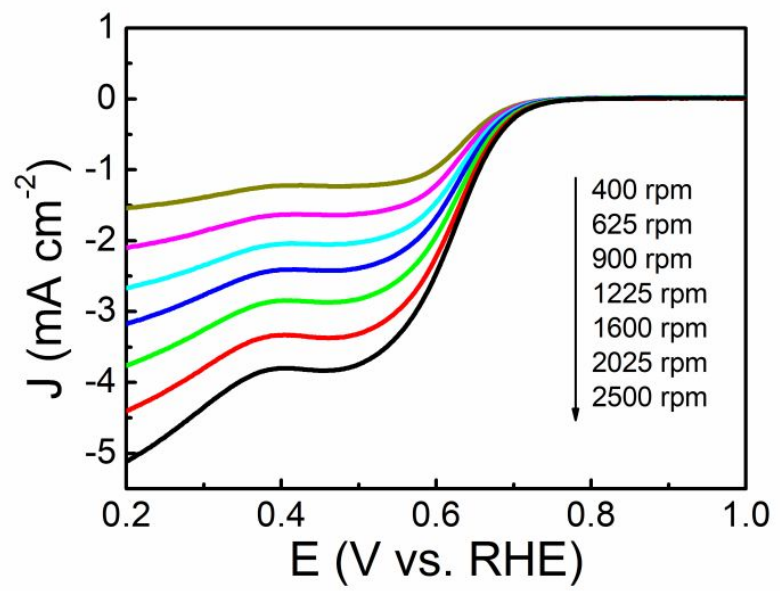

Figure S24. LSV curves of PDA-TAPB-COF at various rotation speeds.

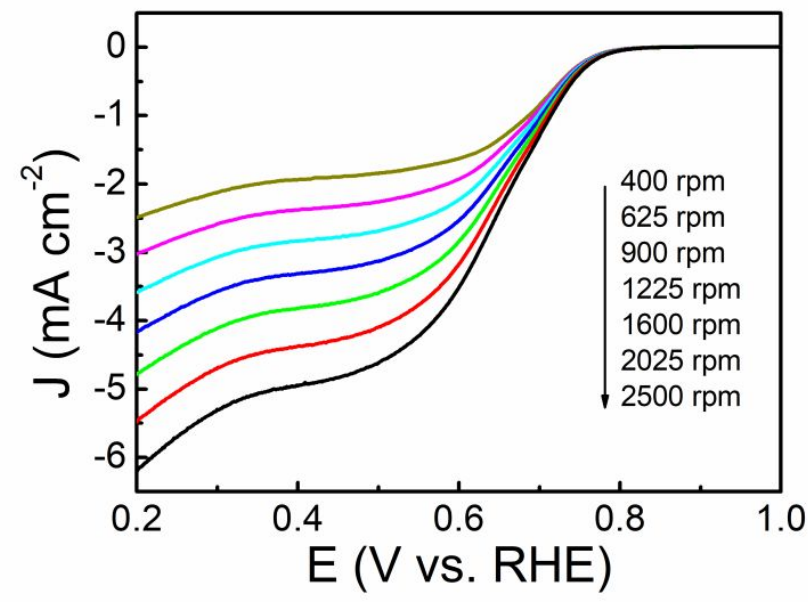

Figure S25. LSV curves of JUC-527 at various rotation speeds.

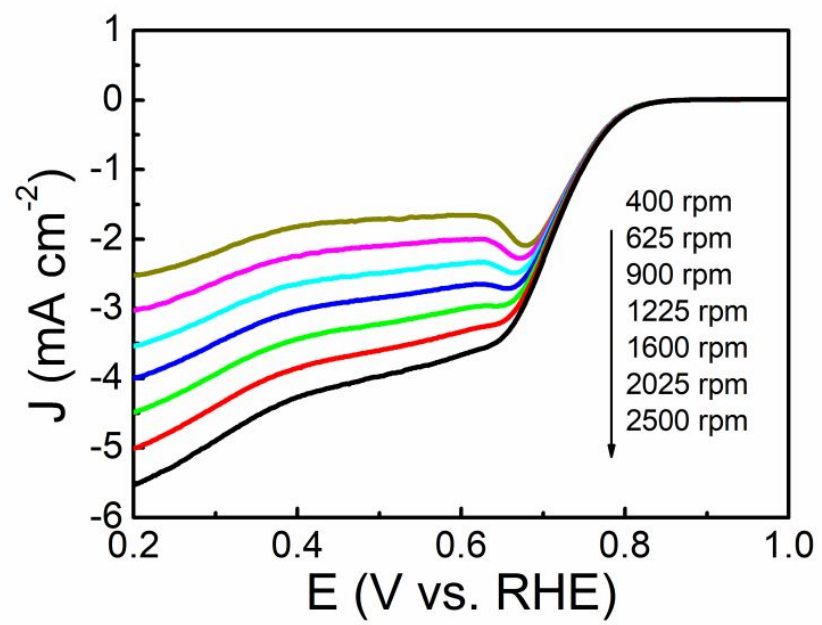

Figure S26. LSV curves of JUC-528 at various rotation speeds. 


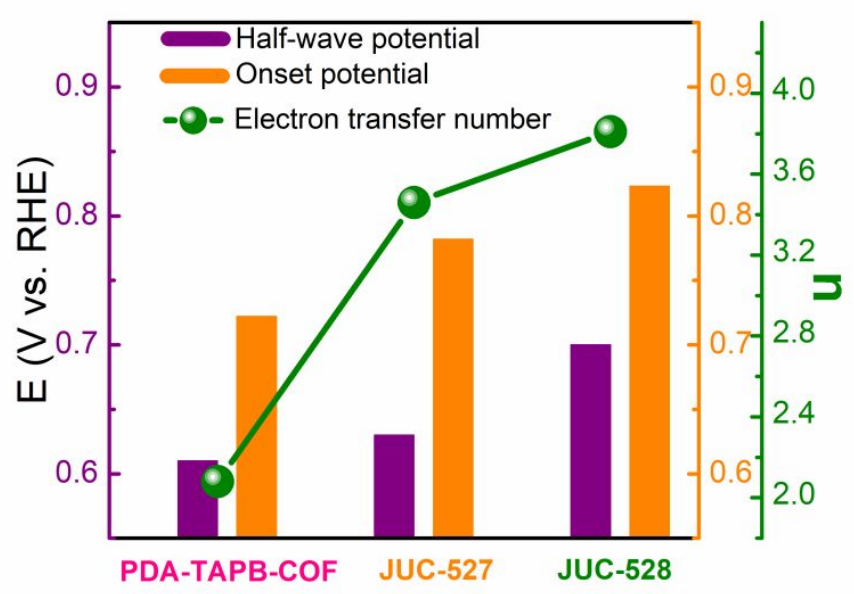

Figure S27. Comparison of onset potential, half-wave potential and electron transfer number of PDA-TAPB-COF, JUC-527, and JUC-528.

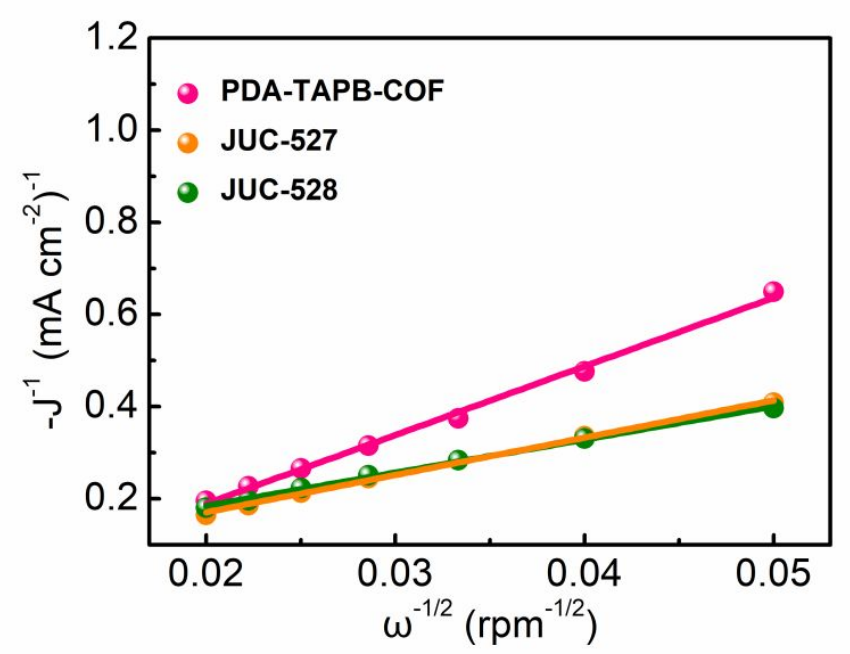

Figure S28. The K-L plots for PDA-TAPB-COF, JUC-527, and JUC-528 at $0.2 \mathrm{~V}$ (vs RHE).

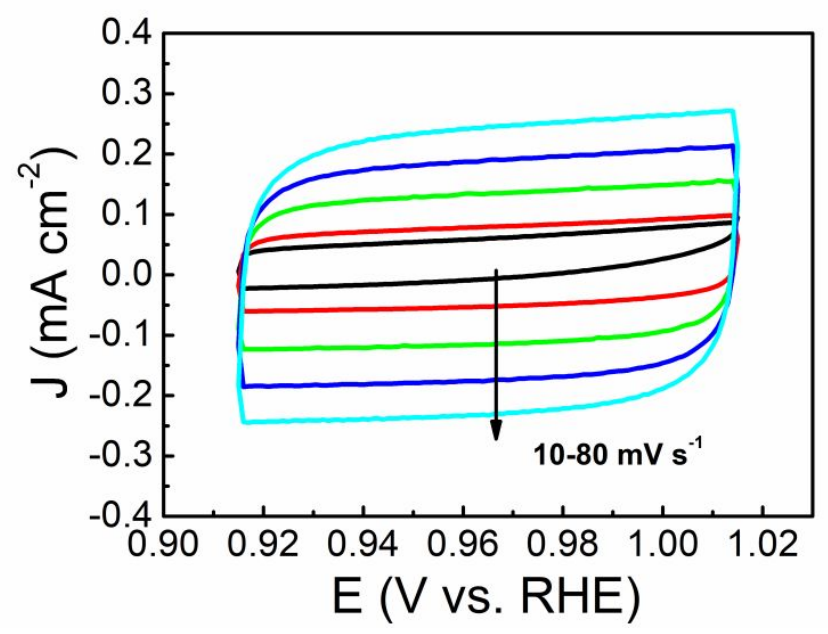

Figure S29. CVs of PDA-TAPB-COF in $0.1 \mathrm{M} \mathrm{KOH}$ solution at different scan rates $(10,20,40,60$, and $80 \mathrm{mV}$ $\left.\mathrm{s}^{-1}\right)$. 


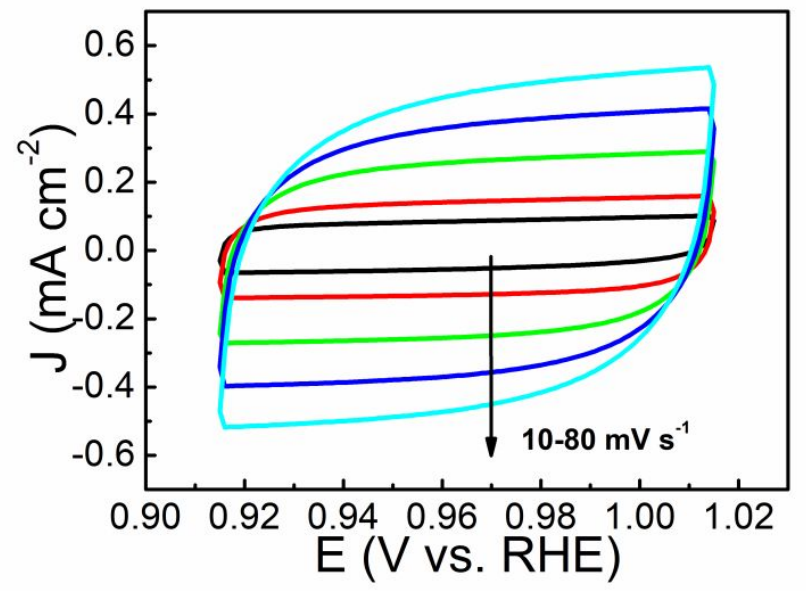

Figure S30. CVs of JUC-527 in $0.1 \mathrm{M} \mathrm{KOH}$ solution at different scan rates $\left(10,20,40,60\right.$, and $\left.80 \mathrm{mV} \mathrm{s}^{-1}\right)$.

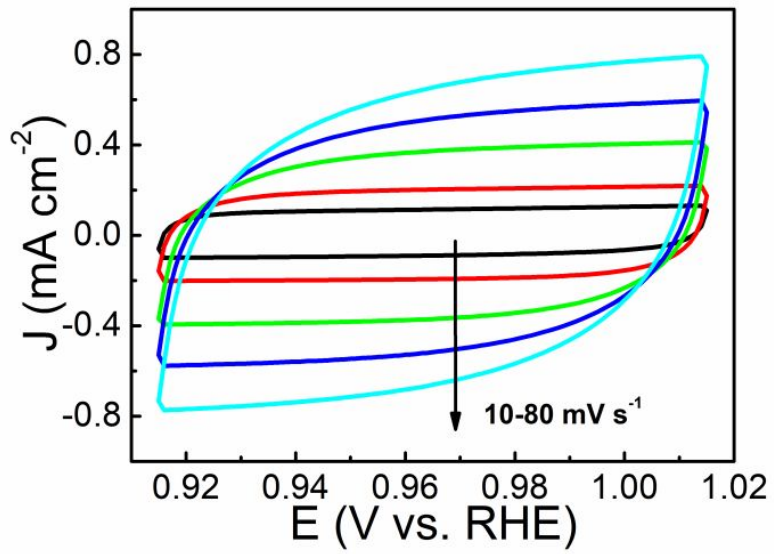

Figure S31. CVs of JUC-528 in 0.1 M KOH solution at different scan rates $\left(10,20,40,60\right.$, and $\left.80 \mathrm{mV} \mathrm{s}^{-1}\right)$.

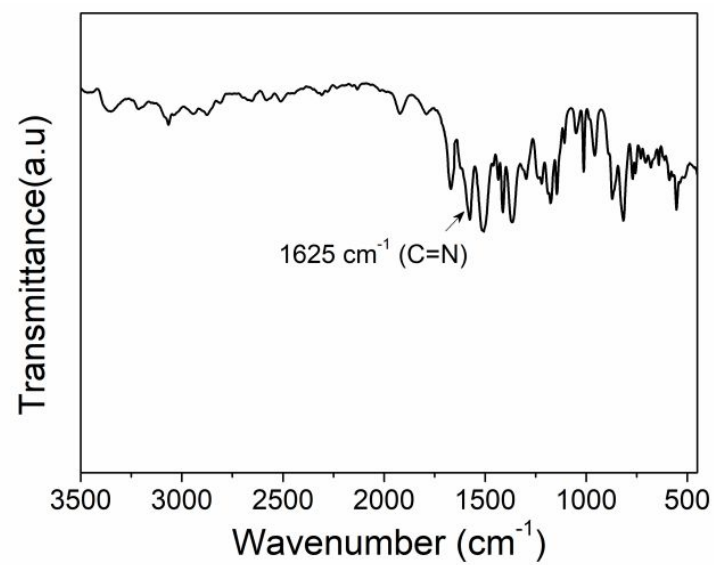

Figure S32. FTIR spectrum of JUC-527 after ORR test at $0.7 \mathrm{~V}$ (vs RHE) for $12 \mathrm{~h}$ in $\mathrm{O}_{2}$-saturated $0.1 \mathrm{M} \mathrm{KOH}$ electrolyte. 


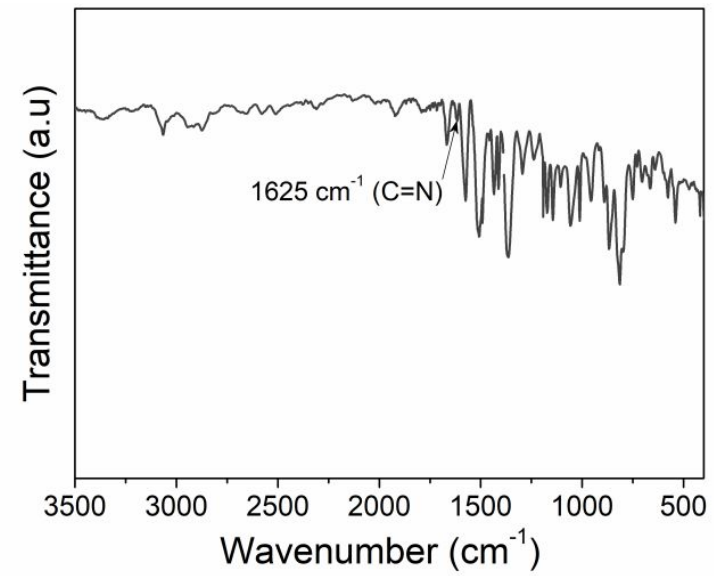

Figure S33. FTIR spectrum of JUC-528 after ORR test at $0.7 \mathrm{~V}$ (vs RHE) for $12 \mathrm{~h}$ in $\mathrm{O}_{2}$-saturated $0.1 \mathrm{M} \mathrm{KOH}$ electrolyte.

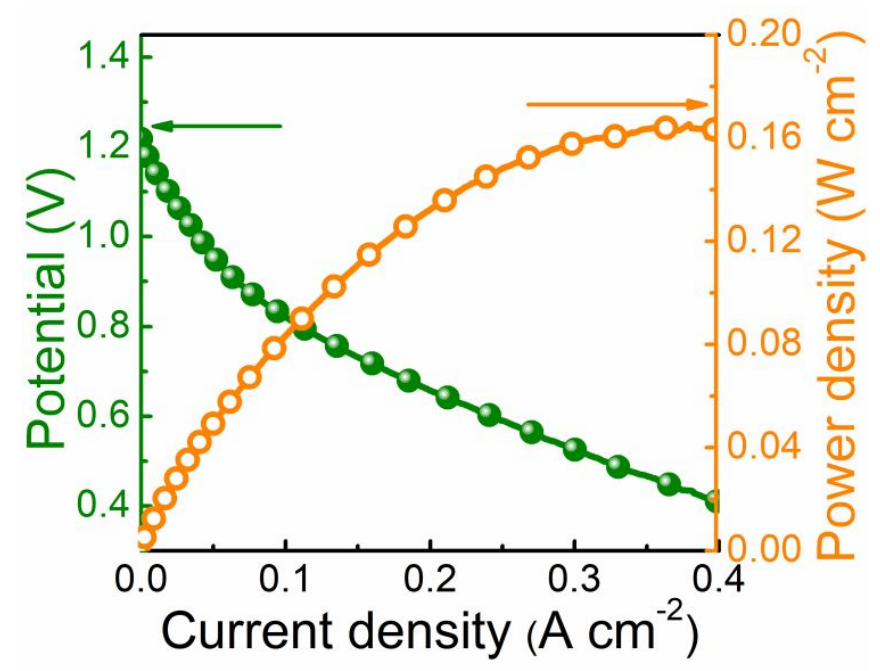

Figure S34. The discharge polarization curve and corresponding power density plot of JUC-528-ZAB.

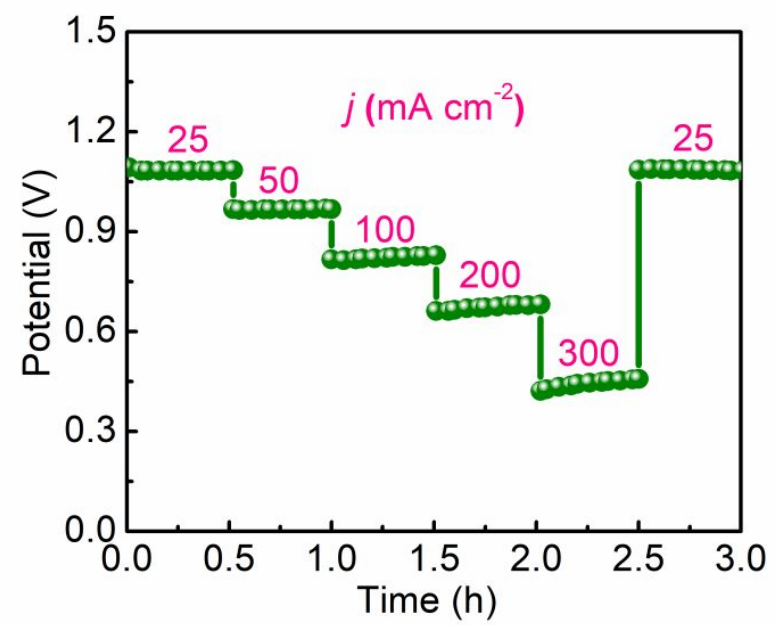

Figure S35. Discharge curves of JUC-528-based ZAB at different current densities $(25,50,100,200,300$ $\left.\mathrm{mA} \mathrm{cm}{ }^{-2}\right)$. 


\section{Theoretical computation section}

Table S3. The free energy values of different sites in PDA-TAPB-COF (Figure 4a).

\begin{tabular}{|c|c|c|c|c|c|c|}
\hline & Site-1/eV & Site- $2 / \mathrm{eV}$ & Site-3/eV & Site-4/eV & Site-5/eV & Site-6/eV \\
\hline overpotential & 0.86 & 1.25 & 0.73 & 0.74 & 1.05 & 0.74 \\
\hline$\Delta \mathrm{G} 1$ & 0.60 & -0.58 & -0.10 & 0.55 & 0.49 & 0.20 \\
\hline$\Delta \mathrm{G} 2$ & -1.46 & -0.23 & -0.70 & -1.29 & -1.57 & -1.26 \\
\hline$\Delta \mathrm{G} 3$ & 0.86 & 1.25 & 0.07 & 0.74 & 1.05 & 0.74 \\
\hline$\Delta \mathrm{G} 4$ & -0.01 & -0.43 & 0.73 & -0.01 & 0.02 & 0.33 \\
\hline
\end{tabular}

Table S4. The free energy values of different sites in JUC-527 (Figure 4b).

\begin{tabular}{ccccccc}
\hline & Site-1/eV & Site-2/eV & Site-3/eV & Site-4/eV & Site-5/eV & Site-6/eV \\
\hline overpotential & 0.89 & 0.67 & 0.70 & 0.74 & 0.91 & 1.29 \\
\hline$\Delta \mathrm{G} 1$ & -0.36 & 0.67 & -0.06 & 0.12 & 0.13 & -0.56 \\
\hline$\Delta \mathrm{G} 2$ & -0.50 & -1.39 & -0.65 & -1.36 & -1.37 & -0.13 \\
\hline$\Delta \mathrm{G} 3$ & 0.89 & 1.00 & 0.02 & 0.49 & 0.91 & 1.29 \\
\hline$\Delta \mathrm{G} 4$ & -0.02 & -0.28 & 0.70 & 0.74 & 0.33 & -0.58 \\
\hline
\end{tabular}

Table S5. The free energy values of different sites in JUC-528 (Figure 4c).

\begin{tabular}{ccccccccc}
\hline & Site-1/eV & Site-2/eV & Site-3/eV & Site-4/eV & Site-5/eV & Site-6/eV & Site-7/eV & Site-8/eV \\
\hline overpotential & 1.01 & 1.02 & 0.71 & 0.54 & 0.56 & 1.15 & 0.59 & 0.80 \\
\hline $\mathrm{G} 1$ & 0.58 & -0.37 & -0.08 & -0.01 & 0.04 & -0.61 & -0.03 & -0.06 \\
\hline$\Delta \mathrm{G} 2$ & -1.64 & -0.37 & -0.66 & -1.34 & -0.62 & -0.23 & -1.39 & -1.37 \\
\hline$\Delta \mathrm{G} 3$ & 1.01 & 1.02 & 0.02 & 0.54 & 0.01 & 1.15 & 0.83 & 0.80 \\
\hline$\Delta \mathrm{G} 4$ & 0.04 & -0.27 & 0.71 & 0.79 & 0.56 & -0.30 & 0.59 & 0.62 \\
\hline
\end{tabular}

